Illinois State University

ISU ReD: Research and eData

Theses and Dissertations

$10-23-2017$

\title{
The Effects Of Physical Activity On Middle School Students' Self- Esteem
}

Marissa Ruchim

Illinois State University, Mlcohen2@ilstu.edu

Follow this and additional works at: https://ir.library.illinoisstate.edu/etd

Part of the Other Education Commons

\section{Recommended Citation}

Ruchim, Marissa, "The Effects Of Physical Activity On Middle School Students' Self-Esteem" (2017).

Theses and Dissertations. 814.

https://ir.library.illinoisstate.edu/etd/814

This Thesis is brought to you for free and open access by ISU ReD: Research and eData. It has been accepted for inclusion in Theses and Dissertations by an authorized administrator of ISU ReD: Research and eData. For more information, please contact ISUReD@ilstu.edu. 


\title{
THE EFFECTS OF PHYSICAL ACTIVITY ON MIDDLE SCHOOL STUDENTS' SELF-ESTEEM
}

\author{
Marissa Ruchim
}

\section{Pages}

The purpose of this study was to investigate the relationship between student physical activity levels during PE days and non-PE days (Encore days) on self-esteem. The study analyzed the differences in participants' self-esteem on days they had PE versus days they had Encore class (i.e. journalism, drama, art, global awareness, stem, and music). Participants were 25 students in an intact sixth-grade PE class (10 girls, 15 boys) at a middle school in a suburb of Chicago. Data were collected from two sources, pedometers recording number of steps taken daily and scores on Harter's Global Self-Worth Scale, a measure of self-esteem. Data were analyzed using SPSS to determine a) average number of steps taken for each participant on PE days, b) number of steps taken by each participant on non-PE days, c) average global self-worth on PE days, d) average global self-worth scores on non-PE days, e) the degree of relationship between the number of steps taken and global self-worth on PE and Encore days, and f) the degree of difference between average steps taken on PE versus non-PE days. Findings indicate that students tend to take more steps on PE days than on Encore days. While students participating in PE do tend to rate their global self-worth slightly higher than when they participate in Encore days, there is no statistically significant relationship between steps taken and global self-worth. 
KEYWORDS: Self-Esteem, Physical Activity, Physical Education, Global Self-Worth 
THE EFFECTS OF PHYSICAL ACTIVITY ON MIDDLE SCHOOL STUDENTS'

SELF-ESTEEM

MARISSA RUCHIM

A Thesis Submitted in Partial

Fulfillment of the Requirements

for the Degree of

\section{MASTER OF SCIENCE}

School of Kinesiology and Recreation

ILLINOIS STATE UNIVERSITY

2017 
Copyright 2017 Marissa Ruchim 
THE EFFECTS OF PHYSICAL ACTIVITY ON MIDDLE SCHOOL STUDENTS'

SELF-ESTEEM

MARISSA RUCHIM

COMMITTEE MEMBERS:

Mary Henninger, Chair

Margaret Coleman

Skip Williams 


\section{ACKNOWLEDGMENTS}

Foremost, I would like to express my sincere gratitude to my chairperson and advisor Prof. Dr. Mary Henninger for the continuous support of my master's study and research, for her patience, motivation, enthusiasm, and immense knowledge. Her guidance helped me in all the time of research and writing of this thesis.

In addition, I would like to thank the rest of my thesis committee: Prof. Dr. Margaret Coleman and Prof. Dr. Skip Williams for their encouragement, insightful comments, and guidance. I would also like to thank my co-teacher, Samantha Villamil, for her assistance and continuous support throughout the data collection process.

Last but not least, I would like to thank my family: my husband Jason Ruchim; my parents Lori Cohen and Michael Cohen; my sister Brittany Cohen; and to all my family and friends for their love and support.

M. R. 


\section{CONTENTS}

Page

ACKNOWLEDGMENTS

CONTENTS

TABLES

CHAPTER I: THE EFFECTS OF PHYSICAL ACTIVITY ON MIDDLE SCHOOL

STUDENTS' SELF-ESTEEM

Introduction $\quad 1$

Methods 3

$\begin{array}{ll}\text { Participants } & 3\end{array}$

School Setting 3

Instrumentation 4

Data Collection Procedures 5

Data Analysis $\quad 6$

$\begin{array}{ll}\text { Results } & 6\end{array}$

$\begin{array}{ll}\text { Relationship Between Steps Taken and Self-Worth } & 7\end{array}$

Relationship Between Steps Taken on PE Days and on Encore Days 7

Relationship Between Self-Worth on PE and Encore Days $\quad 8$

Impact of Steps Taken per Day on Self-Worth $\quad 8$

$\begin{array}{ll}\text { Discussion } & 9\end{array}$

CHAPTER II: EXTENDED LITERATURE REVIEW 13

$\begin{array}{ll}\text { Introduction } & 13\end{array}$

$\begin{array}{ll}\text { Physical Activity } & 14\end{array}$ 
$\begin{array}{lc}\text { Physical Activity and Self-Esteem } & 18\end{array}$

$\begin{array}{ll}\text { Conclusion } & 22\end{array}$

$\begin{array}{ll}\text { REFERENCES } & 23\end{array}$

$\begin{array}{ll}\text { APPENDIX A: STUDENT ACTIVITY LOG } & 28\end{array}$

APPENDIX B: STUDENT ACTIVITY LOG 29

APPENDIX C: GLOBAL SELF-WORTH SURVEY 30 


\section{TABLES}

Table

Page

1. Descriptive Statistics 


\section{CHAPTER I: THE EFFECTS OF PHYSICAL ACTIVITY ON MIDDLE SCHOOL STUDENTS' SELF-ESTEEM}

\section{Introduction}

In the United States, $26 \%$ of students ages 12-19 are considered overweight or obese (CDC, 2017). Overweight and obesity can be affected by a variety of factors, nutrition, physical activity, and heredity to name a few (CDC, 2017). One major concern expressed by the Centers for Disease Control and Prevention (CDC) is that only 29\% of students ages 9-12 get the required 60 minutes of daily physical activity (CDC, 2017). Guo et al. (2015) discusses that Hispanic and Black youth are an at-risk community with limited resources for physical activity, which is the primary demographic of this school. The site for this study enrolled 1,006 students in which 90.5\% were Hispanic, 3.5\% were White, 3.5\% were Black, 1.4\% were Asian, and 1.1\% were more than one race. $91 \%$ of those students were from low-income households. The "at risk" population of the students at this school were in need of an intervention.

Additional barriers this school was facing, which identified the need for this research, was the reconstruction of the district. Since reorganization of the district was rushed, construction was not complete at the start of the 2014-2015 school year. The delayed construction primarily affected the Wellness team with students only receiving PE every 6th day as the school operated on a block schedule (A/B). In 2015-2016, the wellness department had an active space for each of the 6 classes to use, with students receiving PE every other day on a block schedule. With increased time in PE, students had more chances to release stress. From the 2014-2015 school year to the 2016-2017 school year, discipline referrals decreased by 53\%, according to the school records, in which research supports could be attributed to increased activity time in PE. Guo et al. (2015) supports this in discussing that physical activity is a way 
for adolescents to raise self-esteem, reduce stress, and to reduce risky behaviors such as bullying, drug use, violence, and school drop outs. Positive improvements in student self-esteem could result from daily PE where students are guaranteed structured physical activity time.

Low activity levels could be a contributing factor to depression, anxiety, and low levels of self-esteem. Weiss, Phillips, \& Kipp (2015) stated that "Intervention strategies in various youth physical activity settings are needed to prevent risks for obesity, cardiovascular disease, and Type 2 diabetes and to promote opportunities to improve skeletal, cognitive, and mental health" (Weiss, Phillips, \& Kipp, 2015, p. 546). Current research supports the positive relationship between self-esteem and physical activity. Garnett, Becker, Vierling, Gleason, DiCenzo, \& Mongeon (2017), examined a before school physical activity program and its impact on students' behavior and academics. Results indicated that their "Move It! Move It!" program positively influenced student behavior, self-esteem, and school climate. Although not measured in this study, physical activity has many other benefits on adolescents. Martin et al. (2016) discusses that benefits of adequate physical activity in adolescents also include cognitive, emotional, social, and physiological benefits. Improvements in activity levels among students can help not only raise self-esteem, but also increase attention in class, reduce stress, reduce bullying, and improve the overall school climate.

$\mathrm{PE}$ is one of the few places where designated time is provided for students to receive physical activity, which makes it a great environment for this study. Continued issues related to low self-esteem of students and the fact that obesity rates in this district are at all-time high, signify the need for this research.

This study will produce results that can aid in minimizing gaps in research in this field. Results of studies are somewhat inconsistent. Some investigations reveal that physical 
activity has a significant impact on levels of self-esteem among adolescents. Other research fails to identify what specifically affects levels of self-esteem.

Therefore, the purpose of this study was to investigate the relationship between student physical activity levels during PE days and non-PE days (Encore days) on self-esteem. The research questions are as follows: 1 . Will students have higher self-esteem on days they have PE as opposed to days they have their Encore class? 2. Do students that log more overall steps have higher levels of self-esteem? It is hypothesized that students will show higher self-esteem on days they have PE as opposed to the days in which they have their Encore class (i.e. art, music, stem, global awareness, journalism, drama).

\section{Methods}

\section{Participants}

The sample size consisted of 25 students in an intact sixth-grade PE class (10 girls, 15 boys). Demographics for the participants mirrored those of the district with respect to race and

overweight and obese percentages. More than $50 \%$ of students at the study site were considered overweight or obese (Romain, 2014).

\section{School Setting}

Data collection took place at a middle school located in a large suburb in the Midwest. Students at this school spend 75 minutes in each class rotating every other day between wellness class and an Encore class (i.e. music, art, stem, global awareness, journalism, drama). For example, during a two-week period, students attend five PE classes and five days' worth of Encore classes. Data were collected during the last month of the school year at a time when the PE department had limited space and resources due to renovation of the outdoor teaching space. Because of this, the units were limited to "mini-games", track, basketball, and fitness, which the 
students rotated through after each class. The spaces were shared by two classes rather than having one class in a space at a time.

\section{Instrumentation}

Data were collected in three ways. First, physical activity levels were measured through the collection of pedometer data. Second, students' self-esteem was measured using the Global Self-Worth Survey developed by Harter (1985). Finally, activity logs were kept for each day of data collection.

Pedometers. The pedometers used for this research were the Digi-Walker SW-701 model by New Lifestyles, which measures steps taken and calculates distance by multiplying the number of steps taken by stride length. This model accepts stride lengths in increments of .25 feet. This pedometer is constructed with an internal sensor mechanism which uses a coiled spring-suspended leveler arm to count steps. (The Pedometer Company, 2017)

Global Self-Worth Survey. The global self-worth survey used for data collection was derived from the Manual for the self-perception profile for children, developed by Dr. Susan Harter (1985). According to Harter, global self-worth can be used interchangeably with selfesteem. The global self-worth subscale is an overall measure of how well students like themselves and if they are happy with themselves and the way they are leading their lives. This Global Self-Worth Scale was chosen because it is intended for use with students aged 914 years old (grades 3-8). Global self-worth was measured with a subscale of the SelfPerception Profile for Children, a self-reporting inventory for assessing children's and adolescents' perceptions of themselves in various specific domains of their life, as well as their sense of global self-worth (Harter, 1985). The scale consists of five items. Responses are divided into two columns each with two response choices. Starting at the left, items are coded 
as follows: Really True for $\mathrm{Me}=1$, Sort of True for $\mathrm{Me}=2$, Sort of True for $\mathrm{Me}=3$, and Really True for $\mathrm{Me}=4$. Reverse coding is necessary. Items 3, 4, and 5 are reverse coded. Items are reverse coded so that " 4 " does not always reflect either the highest score or the lowest score, which encourages students to carefully select their true response. Responses are then summed to produce a global self-worth score. The higher the score the greater the child's self-worth, 6 being the lowest score to reflect lower self-esteem and 24 being the highest score to reflect higher self-esteem. Reliability for this subscale has an Alpha score of .84.

Activity logs. Two separate activity logs were created asking participants to provide data to be analyzed. One activity log was directed for participants to track their data on PE days. This activity log directed participants to track their anonymous identification number, the date, number of steps taken before PE class, number of steps taken after PE class, and their total number of steps taken for that day. The second activity log was directed for participants to track their data on Encore days. This activity log directed participants to track their anonymous identification number, the date, and their total number of steps taken for that day. Activity monitor data was logged daily using an electronic spreadsheet provided by the principal investigator.

\section{Data Collection Procedures}

Participants $(n=25)$ were selected as an in-tact sixth grade class. Selection criteria included grade level, class functionality, student engagement, and likelihood of the class following data collection procedures. This grade level was more likely to participate with fidelity than my eighth grade class, for example, due to the fact that they were approaching graduation. As part of the school's yearly curriculum, participants completed an activity log (see Appendices A and B) 20 times during the four-week period (10 days PE, 10 days Encore) as well 
as a global self-worth survey (see appendix C). As students walked into the building each day, they stopped in the main office to pick up their pedometer and activity log. Participants were distributed the same pedometer each day that corresponded with their identification number. At the end of each school day, participants once again stopped in the main office to drop off their pedometers and their completed activity log. At this time, students completed their global selfworth survey with their identification number in order to protect anonymity. Pedometers and activity logs were filed and locked in a drawer.

Pedometer data were logged in daily using an electronic spreadsheet provided by the principal investigator. Each day, activity monitors were zeroed out to collect data for a new cycle. The principal investigator ensured that each student's pedometer was working and cleared before distributing them. Participants were taught how to properly use the pedometers and were instructed not to "shake" pedometers in order to count false steps.

\section{Data Analysis}

Data were analyzed using SPSS 23 to determine a) average number of steps taken for each participant on PE days, b) number of steps taken by each participant on non-PE days, c) average global self-worth on PE days, d) average global self-worth scores on non-PE days, e) the degree of relationship between the number of steps taken and global self-worth on PE and Encore days, and $f$ ) the degree of difference between average steps taken on PE versus non-PE days.

\section{Results}

Descriptive statistics for the total sample are presented as means \pm SD. means for a) average number of steps taken for each participant on PE days, b) number of steps taken by each 
participant on non-PE days, c) average global self-worth on PE days, and d) average global selfworth scores on non-PE days were computed along with demographic information (see Table 1). Relationship Between Steps Taken and Self-Worth

Correlation coefficients were computed to determine if there was a relationship between steps taken and global self-worth for PE and Encore days. Results of Pearson correlations are displayed in Table 2. The correlation between PE steps and PE self-worth was -0.163 , indicating that students who took more steps tended to have lower self-worth. However, this correlation is not statistically significant $(\mathrm{p}=0.437)$. The correlation between Encore steps and Encore selfworth is -0.231 , indicating that students who took more steps tended to have lower self-worth. However, this correlation is not statistically significant $(p=0.267)$.

\section{Relationship Between Steps Taken on PE Days and on Encore Days}

Paired Samples Correlation coefficients were computed to determine the relationship between steps taken on PE days versus steps taken on Encore days. The correlation between the steps taken in each condition is 0.59 (weak to moderate in strength) and statistically significant $(p=0.002)$. In short, students that took more steps on PE days tended to also take more steps on Encore days.

A Paired Samples t-test was conducted to compare the average number of steps taken on PE days to the average number of steps taken on Encore days. Results of the Paired Samples ttest are displayed in Table 3. Students took about 2,115 more steps during PE class than in Encore. This difference is statistically significant $(\mathrm{p}<0.001)$. Please note the standard deviation and confidence interval for the difference between the two classes and the t-score from the t-test. 


\section{Relationship Between Self-Worth on PE and Encore Days}

Paired Samples Correlation coefficients were computed to determine the relationship between Self-worth on PE days versus Self-worth on Encore days. The correlation between the SW reported in each condition is 0.954 (very strong) and statistically significant $(\mathrm{p}<0.001)$. In short, students that reported higher SW on PE days tended to also report higher SW on Encore days.

A Paired Samples t-test was conducted to compare the average number of steps taken on PE days to the average number of steps taken on Encore days. Results of the Paired Samples ttest are displayed in Table 4. Students reported a higher SW during PE class than in Encore, by about 0.46 points. This difference is statistically significant $(\mathrm{p}=0.025)$. Please note you also have the standard deviation and confidence interval for the difference between the two classes and the t-score from the t-test.

\section{Impact of Steps Taken per Day on Self-Worth}

To measure the effects of steps taken on Self-Worth, data were rearranged into two columns, with one column containing the average steps taken per day for both PE and Encore days and the other column containing self-worth ratings for both PE and Encore days. By doing so, the sample size for this analysis was increased to 50 (25 participants $\mathrm{x} 2$ conditions). To determine the effect of steps taken on self-worth, a Pearson Correlation was run. The overall correlation between steps taken and self-worth is -0.074 (very weak) and non-significant ( $\mathrm{p}=$ 0.305). Next, a linear regression was conducted to determine if the number of steps taken were a good predictor of self-worth. Results from the linear regression are displayed in Table 5. While the constant (y-intercept) is statically significant, steps taken is not predictive of self-worth at all 
$(p=0.609)$. In short, the number of steps taken does not predict self-worth scores and thus selfesteem levels in this particular setting.

\section{Discussion}

"Low activity levels could be a contributing factor to depression, anxiety, and low levels of self-esteem" (Weiss, et al., 2015). The purpose of this study was to investigate the relationship between student physical activity levels during PE (PE) days and non-PE days (Encore days) on self-esteem. The study analyzed the differences in participants' self-esteem on days they had PE versus days they had Encore class (i.e. journalism, drama, art, global awareness, stem, and music). Data revealed that students tend to take more steps on PE days than on Encore days. While students participating in PE do tend to rate their global self-worth slightly higher than when they participate in Encore days, there is no statistically significant relationship between steps taken and global self-worth. Data from this study mostly resulted in different findings from other current research, although some studies also showed no significant relationship between physical activity levels and self-esteem.

The results of this study were interesting, as they displayed results different to a variety of completed studies, but also had some similar outcomes compared with others. The most significant similarity among findings was that students received more physical activity through the implementation of PE class as well as various intervention programs. For instance, this study revealed that students tend to take more steps on PE days than on Encore days. This is supported by the conclusions from a study done by Basch (2011), who found that increasing students' physical activity and physical fitness can best be achieved through a comprehensive approach that includes PE. Weiss et al. (2015) evaluated the impact of an existing physical fitness program (CHAMPIONS) implemented during PE investigating various factors, including self- 
perceptions and behavioral conduct over a school year. Findings revealed that the CHAMPIONS program is effective in improving or maintaining physical activity levels and related issues among middle school youth.

Another study by Manley et al. (2014) supported current study in the sense that there was no strong statistical significant between the variables in the study. Results suggested that those with more optimal BMI, in comparison to higher steps in this study, had higher levels of selfesteem. This was similar to the current study showing that students who tended to have higher steps on PE days also tended to have higher steps on Encore days, while having higher selfesteem overall.

The current study revealed that students who tend to report higher self-worth in PE also tend to report higher self-worth on Encore days. Additionally, students that report higher selfworth in PE also tend to report higher self-worth on Encore days. Conclusively for this study, it does not appear that steps taken in any condition are associated with the self-worth reported in that condition. This differs from other current research that shows a positive correlation between physical activity levels and self-esteem. For example, in the Move It! Move It! Program initiated by Garnet et al. (2017), quantitative results showed that participants of this before school run/walk program had a positive impact on student behavior and the school climate. Another study by Kiviruusu et al. (2015), supports that, especially among females, higher levels of BMI is associated with lower self-esteem, which highlights the need for interventions to increase activity levels among adolescents. Furthermore, results from a study by Liu, $\mathrm{Wu}$, and Ming (2015) supported the hypothesis for this research where interventions of physical activity are associated with increased self-concept and self-worth in children and adolescents. 
Although not investigated in this study, current research supports that physical activity has many other benefits shown in adolescents. Verret, Guay, Berthiaume, Gardiner, Béliveau (2012) conducted a study exploring the effects of a moderate to high-intenstity physical activity program on fitness, cognitive functions, and ADHD-related behavior in children with ADHD. Findings of this study showed that participation in a physical activity program improves muscular capacities, motor skills, behavior reports by parents and teachers, and level of information processing. Another study by Srikanth, Petrie, Greenleaf, and Martin (2015) examined the influence of physical variables on math and reading achievement test scores. Findings of this study support schools re-examining policies and scheduling that have limited student participation in physical education class.

In the current study, while students did report a slightly higher global self-worth during $\mathrm{PE}$, the steps taken is not the variable predicting the increase. It could be that simply participating in PE classes versus Encore classes affects their self-worth, or another factor that was not considered and measured in this study. An additional variable could have helped to differentiate between self-worth on PE days versus Encore days. One way to differentiate might be to initiate some sort of physical activity program as an intervention, rather than beginning data collecting into an already established routine. Another way to differentiate might be to collect PE data for the first two weeks and Encore data for the second two weeks, resulting in clearer results of what self-esteem levels were attributed to. The absence of a strong correlation between PE days, activity steps, and self-worth could be attributed to a variety of reasons. Perhaps in this study, based on the repeated nature of data collection, students were aware of the prospected correlation between higher steps and higher self-worth scores and student responses were reflective of this. Students could have experienced participant fatigue in filling out the same 
global self-worth survey each day, and learning which responses were considered more positive, thus resulting in a higher score. Since the current study only showed a significant relationship between higher steps on PE days than Encore days, future research should be done with additional variables to determine what factor(s) affect self-worth. 


\section{CHAPTER II: EXTENDED LITERATURE REVIEW}

\section{Introduction}

The purpose of this study was to investigate the relationship between student physical activity levels during PE days and non-PE days (Encore days) on self-esteem. The study analyzed the differences in participants' self-esteem on days they had PE versus days they had Encore class (i.e. journalism, drama, art, global awareness, stem, and music). Data was collected from two sources, pedometers recording number of steps taken daily and scores on a measure of self-esteem as measured by Harter's Global Self-Worth Scale (Harter, 1985). Data were analyzed using SPSS to determine a) average number of steps taken for each participant on PE days, b) number of steps taken by each participant on non- PE days, c) average global self-worth on PE days, d) average global self-worth scores on non- PE days, e) the degree of relationship between the number of steps taken and global self-worth on PE and Encore days, and f) the degree of difference between average steps taken on PE versus non- PE days. Supporting research were derived from searching within the fields of Kinesiology and Psychology (SPORTDiscus; PsycInfo (EBSCOhost)) using the terms self-esteem, physical activity, adolescents, and middle school students. Articles were included that focused on how physical activity impacted selfesteem, or that illustrated current trends of physical activity and self-esteem. Articles were excluded that focused on participants outside of the age range of school-aged children, or that discussed overweightness and obesity. This review of literature is organized into three sections: (a) Physical activity, (b) Self-esteem, and (c) Physical activity and self-esteem. 


\section{Physical Activity}

Physical activity is defined as "any bodily movement produced by skeletal muscles that requires energy expenditure" (Edwards, Bryant, Keegan, Morgan, Jones, 2017, p. 114). PE is a significant reliable source of high quality PA. Trends across research consistently identify a positive correlation between increased physical activity and reduced risk of health-related diseases. Edwards, et al. (2016) continues to describe physical activity as an element that has consistently resulted in health benefits, such as reducing the risk of cardiovascular disease, diabetes, and cancer in both children and adults. Wojcicki (2015) supports Edwards' et al. claim through findings that indicate the more a person participates in any type of physical activity, the less chances they have of developing health related illness.

Lack of physical activity has been directly linked to the global epidemic of obesity, which is a precursor to health-related diseases (McHugh, 2016). He explains that body weight is commonly classified using Body Mass Index (BMI), with standards linked to obesity of having a BMI greater than or equal to 30 . "Obesity is also defined as an excessive fat accumulation that

presents a risk to health" (McHugh, 2016, p. 94). McHugh continues to explain that obesity is a result of consuming more calories than one burns, which has become a preventable epidemic on the rise. He states an astounding statistic that "before they reach the age of five, 40 million of the world's children will have become obese" (McHugh, 2016, p.94). Obesity has become a global epidemic that is $100 \%$ preventable given appropriate interventions put in place to reverse these trends.

Despite research supporting the presence of an obesity epidemic and lack of physical activity being a precursor to the risk of health-related diseases, researchers/teachers are currently seeing the lowest rates of physical activity as well as the highest rates of obesity and health- 
related diseases in both adolescents and adults (CDC, 2017). In order to receive health-related benefits, the Center for Disease Control and Prevention (CDC, 2016) recommends that adults participate in at least 150 minutes ( 2 hours and 30 minutes) a week of moderate-intensity, or 75 minutes ( 1 hour and 15 minutes) a week of vigorous-intensity aerobic activity. For children and adolescents, the CDC (2016) recommends 60 minutes (1 hour) or more of physical activity daily. Physical activity and exercise should include a variety of aerobic, muscle strengthening, and bone-strengthening activities. For various physical, social/emotional, and mental factors, there tends to be a significant drop off in activity levels of youth as they enter pubescent years. According to Carter, Dellucci, Turek \& Mir (2015), levels of physical activity decline when youth aged children enter adolescence. To further support this point, physical activity levels among adolescents are at all-time lows with less than one in five American adolescents reporting regular participation (CDC, 2017). Not only are physical activity levels at all-time lows, but "current PA levels in children and adolescents are insufficient to achieve health benefits" (Olivares, Cossio-Bolaños, Gomez-Campos, Almonacid-Fierro, Garcia-Rubio, 2015, p.114). One identified reason for the decrease in physical activity levels is due to increased access and use of technology. It was stated that "contributing to this problem is the fact that pursuits of sedentary behaviors (e.g., watching television, playing video games) by this demographic have steadily and significantly increased over the last few decades" (Pate, Mitchell, Byun, \& Dowda, 2011). With increased access to technology including cell phones, tablets, televisions, and videogames, youth are spending more time in front of a screen and less time engaging in physical activity. In addition to increased screen time, adolescents face a period in life where they are in search of self and where and with whom they fit it. They spend less time playing outside and participating in sports and more time worrying about the social aspects of middle 
school and high school (Guo et al., 2015. If physical educators can intervene with families, communities, schools, and PE classes to increase the activity levels of our youth, we can begin combat its negative effects of obesity and health-related diseases.

One way researchers suggest we combat this epidemic is to offer student choice within a curriculum of PE. For students to increase their levels of physical activity and become lifelong learners, they need to find a sense of enjoyment in physical activity. If students are exposed to a variety of physical activities and then given a choice for participation, research supports they are more likely to participate and engage (Hill \& Hannon, 2008). Hill and Hannon (2008), suggest that, for PE and physical activity to have a stronger presence in schools, PE teachers need to consider the interests and needs of their students when developing the curriculum. The researchers continue to explain that student choice might be based on societal or environmental influences that may be reinforced by the media, ethnicity, cultural values, or role models. All of

these aspects, societal and environmental influences, gender, student age, student skill level, and level of student physical activity outside of school hours, need to be considered by physical educators in an effort to facilitate student learning and increase levels of physical activity in our youth aged students. As a result, higher rates of participation and engagement will directly result in progress towards combating current trends

\section{Self-Esteem}

Self-esteem is defined as "a positive or negative orientation towards one-self, as an overall evaluation of one's worth or value" (Rose, Slaten, \& Preast, 2017, p. 160). In laymen's terms, self-esteem is a measure of how one feels about themselves and their level of self-worth. Rose, et al. (2017) continues to explain that self-esteem is an individual factor that can be influenced by various social and environment components throughout a child's life and that high 
or low self-esteem is directly relating to bullying. Self-esteem and related bullying behaviors can have an immense effect on the morale within a school community. How one feels about themselves is directly related to how a student feels in the school setting, what they choose to participate in, and how they value their education. Further research supports this idea and states that "victims of bullying tend to have lower self-esteem as well as higher levels of depression and anxiety (Malecki et al., 2015, p. 117). A student's level of self-esteem is a crucial element in the sense of a community within a school that is multi-dimensional, including students, teachers, and administration.

Another factor related to self-esteem and physical activity is adolescent development. Guo, et al. (2015) discussed the intense developmental period that is associated with the adolescent years. Adolescents are in search of an identity and sense of self at the most crucial time when they encounter many challenging situations (bullying, parent-child conflict, friend rejection, peer pressure) that can have a large impact on their level of self-esteem. Further, these situations often result in "negative outcomes such as low self-esteem, internalizing symptoms, and aggression" (Guo, et al., 2015, p. 2,337). At this age, students with low-self-esteem tend to cope with not feeling good about themselves by drinking, doing drugs, getting into fights, disengaging in the learning process, and dropping out of school. However, research has identified that various intervention programs can help to reverse these trends of bad behaviors.

Current research also highlighted specific trends relating to low levels of self-esteem relating to body image in both males and females, but most specifically related to females. Grosick, Talbert-Johnson, Myers, and Angelo (2013) administered surveys of middle school students that discussed self-esteem. Results revealed that many students are affected by the pressure to be thin, as it is presented in the media. Many of the students in the study admitted to 
having been on a diet to lose weight, having been depressed or concerned about their appearance, or having been pressured by family, friends, teachers, or coaches to lose or gain weight (Grosick, et al., 2013). In addition, a small number of female adolescents in the study admitted to or are thinking about binging and purging to lose weight (Grosick, et al., 2013). Unfortunately, it is inevitable that these thoughts are prevalent in adolescent minds as they are surrounded by a society that portrays unrealistic body images in every media outlet.

For the purpose of measuring self-esteem for this thesis, a global self-worth subscale was used, which was derived from the Self-Perception Profile for Young Children (Harter, 1985). The global self-worth subscale was developed for children aged 8-14 years old (grades 3-8) and is extremely reliable (alpha score $=.84$ ) in measuring levels of self-esteem for this age group. This subscale is an overall measure of how well children like themselves and whether or not they are happy with themselves and the way they are leading their lives. In order to score this subscale and quantify measures of self-esteem, responses are divided into two columns each with two response choices. Starting at the left, items are coded as follows: Really True for $\mathrm{Me}=1$, Sort of True for $\mathrm{Me}=2$, Sort of True for $\mathrm{Me}=3$, and Really True for $\mathrm{Me}=4$. Reverse coding is necessary. Items 3, 4, and 5 are reverse coded. Responses are then summed to produce a global self-worth score. The higher the score the greater the child's self-worth. This survey was used to quantify levels of self-esteem for the sample size.

\section{Physical Activity and Self-Esteem}

The most overwhelming trend within the topics of physical activity and self-esteem lies in the positive relationship between the two. Current research vastly supports the positive correlation between increased physical activity levels and higher levels of self-esteem. As a PE 
teacher that focuses on promoting healthy lifestyle choices and social-emotional learning, I find it fitting to further dissect this topic.

One commonality across research discusses that those who are overweight or obese, caused by inactivity and poor diet, have a more difficult time maintaining a positive self-image in general. Those identified as overweight or obese are at a disadvantage and often lack the willingness to take steps towards a healthier weight thus resulting in even lower levels of selfesteem. For example, "low self-esteem may hinder successful weight loss and maintenance in the current obesogenic environment, and failures in weight control may further reduce selfesteem" (Kiviruusu, et al., 2015, p. 355). Kiviruusu, et al. (2015) concluded that among females, there is a negative correlation between BMI and self-esteem, as BMI increases, self-esteem lowers. While Kirviruusu et al. focused specifically on adolescents, the article also discussed that low levels of self-esteem persisted into mid-adulthood. The same study discussed results in males, which highlighted the need for interventions to tackle low self-esteem related to weight discrimination for both males and females. Low self-esteem in relation to one's health often leads school aged children to further avoid healthy habits and disengage in physical activity. This idea is supported in another study by Hagger and Stevenson (2010), who found that social physique anxiety is related to physical self-esteem, body image, dissatisfaction with appearance and weight, and eating attitudes. Results of this study were gender specific in that females had lower levels of physical self-esteem than males. Students who suffer from low self-esteem are more likely to disengage in health-related behaviors, such as physical activity. In this instance, school systems need to intervene and teach healthy habits and offer opportunities where our students can take steps to improve. 
Another commonality discussed in research was related to the key physical developmental changes that occur during middle school and how these changes affect a child's self-esteem. During a child's adolescent years, they encounter many physiological, social, and emotional changes that influence health-related behaviors. As described by Carter, et al. (2015), pubescent changes result in depressive symptoms that lead adolescents to isolate themselves and engage in more sedentary behaviors. This increase in sedentary behaviors put adolescents at risk for weight gain. As educators, it becomes increasingly important to recognize their depressive behaviors and intervene in a way which further encourages students to engage in physical activities.

Research supports the association between physical activity and social, emotional, and physical development. According to Basch (2011), physical activity affects emotional stability, physical health, and motivation and ability to learn. Results of Basch's study discuss first that a large proportion of youth is insufficiently physically active, specifically in Black and Hispanic youth. This population of youth with the lowest levels of physical activity also have the least access to physical activity opportunities and resources. Basch (2011) concludes that inactivity has major influences on the brain and spinal cord, resulting in lessened emotional stability and motivation. He explains that increased physical activity is one pathway towards a healthier child. We can begin to combat this by implementing various intervention programs. Martin, et al., (2009) conducted a study where one intervention program was implemented, in which results showed increased self-concept in young girls after a 12-week running program. Martin et al. found that students who perceive physical activity to have a positive effect on their self-esteem are more likely to find value in future participation in physical activities. 
Further research discussed the clear and concise relationship between increased levels of physical activity and higher self-esteem. Daily physical activity has a positive effect on one's overall self-esteem. A study that investigated the effects of participation in regular exercise for 12 weeks on self-esteem and hopelessness of 80 female students by Yigiter (2014) revealed two findings: (1) levels of self-esteem increased significantly after the completion of the exercise program and (2) levels of hopelessness of the experiment group decreased significantly after the completion of the exercise program. The positive relationship between physical activity and self-esteem continue to be supported in research. Another study stated that, "from selfenhancement perspectives (suggesting that more positive self-perceptions lead to more engagement in physical activity) previous studies on adolescents have consistently reported that individuals with higher (more positive) physical self-perception were more physically active" (Lindwall, Asci, Crocker, 552, 2014). More supporting research by Manley, et al. (2014) discussed that physical activity in healthy weight and obese school-age youth is associated with academic benefits and lower rates of depression, anxiety, and improved self-concept. It is evident that higher levels of self-esteem result in higher activity levels as well as higher activity levels result in higher self-esteem.

In the school where the study was conducted, there is a focus on teaching acceptable and appropriate behaviors, which are positively associated with how one feels about themselves. If students feel a great sense of self-worth, they are more likely to find the importance in engaging in appropriate behaviors. This is supported in one study that states that "acute effects of exercise have been associated with reductions in negative behaviors and improvements in acceptable behaviors" (Verret et al., 2012, p. 72). Increased physical activity time within the school day can help our school's initiative towards teaching appropriate behaviors and seeing results within the 
morale of our school. Research supports that more physical activity time will result in more of these behaviors such as higher attendance, self-respect, decrease in bullying, and more participation both during the school day and in extra-curricular activities.

\section{Conclusion}

There have been numerous studies comparing physical activity levels and how they affect self-esteem, specifically in middle school students. According to the previously stated research, increased levels of physical activity can have a positive effect on a student's level of self-esteem (Yigiter, 2014). It is also supported by research that students with higher levels of self-esteem are more likely to choose health-enhancing behaviors, such as being physically active (Basch, 2011). Conclusively, each component of this research, physical activity, and self-esteem, have a positive relationship to the other. However, if a student is already at risk (overweight or obese) or experiencing isolation behaviors during adolescents, they will further struggle to develop healthier habits both physically and emotionally (Carter, et al. 2015).

Several recommendations have been made for teachers and families to intervene when we see students disengaging in physical activity or demonstrating signs of low self-esteem. PE teachers need to focus on the specific interests of their students, which can be in relation to gender, SES status, ethnicity, cultural values, or role models (Hill \& Hannon, 2017). It is crucial

for teachers to consider these ideas when developing curriculum and implementing learning activities. There are steps physical educators can take to combat our obesity epidemic. We can do this by designing learning opportunities to intervene and take steps increase levels of both physical activity and self-esteem in our students. 


\section{REFERENCES}

Basch, C. E. (2011). Physical activity and the achievement gap among urban minority youth. Journal of School Health, 81(10), 626-634.

Carter, J. J., Dellucci, T., Turek, C., \& Mir, S. (2015). Predicting depressive symptoms and weight from adolescence to adulthood: stressors and the role of protective factors. Journal of Youth \& Adolescence, 44(11), 2122-2140.

CDC. Current physical activity guidelines. (2016, November 29). Retrieved September 04, 2017, from https://www.cdc.gov/cancer/dcpc/prevention/policies_practices/physical_activity/gui delines.htm

CDC. Division of nutrition, physical activity, and obesity. (2017, October 02). Retrieved October 19, 2017, from https://www.cdc.gov/nccdphp/dnpao/index.html

Edwards, L., Bryant, A., Keegan, R., Morgan, K., \& Jones, A. (2017). Definitions, foundations and associations of physical literacy: a systematic review. Sports Medicine, 47(1), 113-126. doi:10.1007/s40279-016-0560-7

Garnett, B. R., Becker, K., Vierling, D., Gleason, C., DiCenzo, D., \& Mongeon, L. (2017). A mixed-methods evaluation of the "move it move it!" before-school incentive-based physical activity programme. Health Education Journal, 76(1), 89-101.

Grosick, T. L., Talbert-Johnson, C., Myers, M. J., \& Angelo, R. (2013). Assessing the landscape: body image values and attitudes among middle school boys and girls. American Journal of Health Education, 44(1), 41-52. 
Guo, S., Wu, Q., Smokowski, P., Bacallao, M., Evans, C., \& Cotter, K. (2015). A Longitudinal evaluation of the positive action program in a low-income, racially diverse, rural county: effects on self-esteem, school hassles, aggression, and internalizing symptoms. Journal of Youth \& Adolescence, 44(12), 2337-2358. doi:10.1007/s10964015-0358-1

Hagger, M., \& Stevenson, A. (2010). Social physique anxiety and physical self-esteem: gender and age effects. Psychology \& Health, 25(1), 89-110. doi:10.1080/08870440903160990

Harter, S. (1985). Self-perception profile for children: manual and questionnaires grades 3-8. Denver, CO: University of Denver.

Hill, G., \& Hannon, J. C. (2008). An analysis of middle school students' physical education physical activity preferences. Physical Educator, 65(4), 180-194.

Kiviruusu, O., Konttinen, H., Huurre, T., Aro, H., Marttunen, M., \& Haukkala, A. (2016). Selfesteem and body mass index from adolescence to mid-adulthood. a 26-year followup. International Journal of Behavioral Medicine, 23(3), 355-363. doi:10.1007/s12529$015-9529-4$

Lindwall, M. A., Asci, H. A., Crocker, P. A., Göteborgs universitet, S. P., University of Gothenburg, F. P., Göteborgs universitet, U. P., \& University of Gothenburg, F. P. (2014). The physical self in motion: within-person change and associations of change in self-esteem, physical self-concept, and physical activity in adolescent girls. Journal of Sport \& Exercise Psychology, 551. doi:10.1123/jsep.2013-0258

Liu, M., Wu, L., \& Ming, Q. (2015). How does physical activity intervention improve selfesteem and self-concept in children and adolescents? evidence from a meta-analysis. Plos One, 10(8), e0134804. doi:10.1371/journal.pone.0134804 
Malecki, C. c., Demaray, M. m., Coyle, S. s., Geosling, R. r., Rueger, S. s., \& Becker, L. 1. (2015). Frequency, power differential, and intentionality and the relationship to anxiety, depression, and self-esteem for victims of bullying. Child \& Youth Care Forum, 44(1), 115-131.

Manley, D., Cowan, P., Graff, C., Perlow, M., Rice, P., Richey, P., \& Sanchez, Z. (2014). Selfefficacy, physical activity, and aerobic fitness in middle school children: examination of a pedometer intervention program. Journal of Pediatric Nursing, 29228-237. doi:10.1016/j.pedn.2013.10.011

Martin, J., Garn, A., Ferry, M., McCaughtry, N., Shen, B., \& Fahlman, M. (2016). Multidimensional physical self-concept in underserved urban high school students: predicting physical activity. Journal of Applied Biobehavioral Research, 21(2), 107123. doi:10.1111/jabr.12045

McHugh, B. (2016). The childhood obesity epidemic. Journal of The Australian TraditionalMedicine Society, 22(2), 94-98.

(n.d.). Retrieved October 12, 2017, from http://www.thepedometercompany.com/sw701.html (n.d.). Retrieved October 19, 2017, from http://www.thepedometercompany.com/sw701.html Olivares, P. R., Cossio-Bolaños, M. A., Gomez-Campos, R., Almonacid-Fierro, A., \& GarciaRubio, J. (2015). Influence of parents and physical education teachers in adolescent physical activity. International Journal of Clinical and Health Psychology, 15, 113-120. doi:10.1016/j.ijchp.2015.01.002

Pate, R., J. Mitchell, W. Byun, \& M. Dowda, (2011). Sedentary behaviour in youth British Journal of Sports Medicine, 45, 906-913. 
Romain, Michael. More than half of district 89 sixth graders overweight or obese, Says Loyola Health Experts. (2014). Retrieved June 14, 2016, from https:/thevillagefreepress.org/2014/10/16/more-than-half-of-district-89-sixth-gradersoverweight-or-obese-says-loyola-health-experts/

Rose, C. R., Slaten, C. D., \& Preast, J. L. (2017). Bully perpetration and self-esteem: examining the relation over time. Behavioral Disorders, 42(4), 159-169.

Sedentary behaviour in youth. (2011). British Journal of Sports Medicine, 45(11), 906. doi:10.1136/bjsports-2011-090192

Srikanth, S., Petrie, T. A., Greenleaf, C., \& Martin, S. B. (2015). The relationship of physical fitness, self-beliefs, and social support to the academic performance of middle school boys and girls. Journal of Early Adolescence, 35(3), 353-377.

Verret, C., Guay, M.-C., Berthiaume, C., Gardiner, P., \& Béliveau, L. (January 01, 2012). A physical activity program improves behavior and cognitive functions in children with ADHD: an exploratory study. Journal of Attention Disorders, 16, 1, 71-80.

Weiss, M. R., Phillips, A. C., \& Kipp, L. E. (2015). Effectiveness of a school-based fitness program on youths' physical and psychosocial health outcomes. Pediatric Exercise Science, 27(4), 547. doi:10.1123/pes.2015-0011

Wojcicki, T. R. (2015). A social cognitive approach to influencing adolescent physical activity behavior via social media. Dissertation Abstracts International, 75

Yigiter, K. (2014). The effects of participation in regular exercise on self-esteem and hopelessness of female university students. Social Behavior \& Personality: An International Journal, 42(8), 1233-1243. doi:10.2224/sbp.2014.42.8.12 
Table 1

Descriptive Statistics

\begin{tabular}{lccccc}
\hline & $\mathrm{N}$ & Minimum & Maximum & Mean & Std. Deviation \\
\cline { 2 - 6 } PESteps & 25 & 3276 & 7547 & 511.00 & 990.544 \\
EncoreSteps & 25 & 1369 & 5115 & 2995.75 & 922.304 \\
PESelfWorth & 25 & 15 & 24 & 18.42 & 3.078 \\
EncoreSelfWorth & 25 & 14 & 24 & 17.97 & 3.186 \\
\hline
\end{tabular}




\section{APPENDIX A: STUDENT ACTIVITY LOG}

Student Activity Log

PE Day

Student ID \#:

Date

\begin{tabular}{|l|l|l|l|l|}
\hline Time & Description of Activity & $\begin{array}{l}\text { Start } \\
\text { Time }\end{array}$ & $\begin{array}{l}\text { End } \\
\text { Time }\end{array}$ & Total Time \\
\hline & & & & \\
\hline & & & & \\
\hline & & & & \\
\hline & & & & \\
\hline & & & & \\
\hline & & & & \\
\hline
\end{tabular}

Number of steps BEFORE PE:

Number of steps AFTER PE:
Total Activity Time Today:

Total Number of Steps Today: 


\section{APPENDIX B: STUDENT ACTIVITY LOG}

Student Activity Log

\section{ENCORE Day}

Student ID \#:

\begin{tabular}{|l|l|l|l|l|}
\hline Time & Description of Activity & $\begin{array}{l}\text { Start } \\
\text { Time }\end{array}$ & $\begin{array}{l}\text { End } \\
\text { Time }\end{array}$ & Total Time \\
\hline & & & & \\
\hline & & & & \\
\hline & & & & \\
\hline & & & & \\
\hline & & & & \\
\hline & & & & \\
\hline
\end{tabular}

Total Activity Time Today:

Total Number of Steps Today: 


\section{APPENDIX C: GLOBAL SELF-WORTH SURVEY}

Check only ONE box for each question. For each question, decide first which statement is most like you. Then put an $\mathrm{X}$ in one of the answer boxes next to that statement. It should look like the sample item below.

\begin{tabular}{|c|c|c|c|c|c|c|c|}
\hline & $\begin{array}{l}\text { Really } \\
\text { True for } \\
\text { Me }\end{array}$ & $\begin{array}{l}\text { Sort } \\
\text { of } \\
\text { True } \\
\text { for } \\
\text { Me }\end{array}$ & \multicolumn{3}{|c|}{ Only choose one answer for each question } & $\begin{array}{l}\text { Sort of } \\
\text { True for } \\
\text { Me }\end{array}$ & $\begin{array}{l}\text { Really } \\
\text { True for } \\
\text { Me }\end{array}$ \\
\hline \multicolumn{8}{|c|}{ Sample Item } \\
\hline $\begin{array}{l}\text { S } \\
\text { A } \\
\text { M } \\
\text { P } \\
\text { L } \\
\text { E }\end{array}$ & & & $\begin{array}{l}\text { Some kids } \\
\text { would } \\
\text { rather play } \\
\text { outdoors in } \\
\text { their spare } \\
\text { time. }\end{array}$ & BUT & $\begin{array}{l}\text { Other kids would } \\
\text { rather watch T.V. }\end{array}$ & $\mathbf{X}$ & \\
\hline \multicolumn{8}{|c|}{ Now continue....... } \\
\hline 1. & & & $\begin{array}{l}\text { Some kids are } \\
\text { often unhappy } \\
\text { with } \\
\text { themselves. }\end{array}$ & BUT & $\begin{array}{l}\text { Other kids are pretty } \\
\text { pleased with } \\
\text { themselves. }\end{array}$ & & \\
\hline 2. & & & $\begin{array}{l}\text { Some kids } \\
\text { don't like the } \\
\text { way they are } \\
\text { leading their } \\
\text { life. }\end{array}$ & BUT & $\begin{array}{l}\text { Other kids do like } \\
\text { the way they are } \\
\text { leading their life. }\end{array}$ & & \\
\hline 3. & & & $\begin{array}{l}\text { Some kids } \\
\text { are happy } \\
\text { with } \\
\text { themselves } \\
\text { as a person. }\end{array}$ & BUT & $\begin{array}{l}\text { Other kids are } \\
\text { often not happy } \\
\text { with themselves. }\end{array}$ & & \\
\hline 4. & & & $\begin{array}{l}\text { Some kids } \\
\text { like the kind } \\
\text { of person } \\
\text { they are. }\end{array}$ & BUT & $\begin{array}{l}\text { Other kids often } \\
\text { wish they were } \\
\text { someone else. }\end{array}$ & & \\
\hline
\end{tabular}




\begin{tabular}{|l|l|l|l|l|l|l|}
\hline 5. & $\square$ & $\begin{array}{l}\text { Some kids are } \\
\text { very happy } \\
\text { being the way } \\
\text { they are. }\end{array}$ & BUT & $\begin{array}{l}\text { Other kids wish } \\
\text { they were } \\
\text { different. }\end{array}$ & $\square$ \\
\hline 6. & $\square$ & $\begin{array}{l}\text { Some kids } \\
\text { are not very } \\
\text { happy with } \\
\text { the way they } \\
\text { do a lot of } \\
\text { things. }\end{array}$ & BUT & $\begin{array}{l}\text { Other kids think } \\
\text { the way they do } \\
\text { things is fine. }\end{array}$ & $\square$ \\
\hline
\end{tabular}

This subscale is derived from the Self -Perception Profile for Young Children (Harter, 2012). 